\title{
INTERIORIDAD Y PROFUNDIDAD. RELACIÓN ENTRE SØREN KIERKEGAARD Y PAUL TILLICH ${ }^{1}$
}

\author{
Mg. Jaime Laurence Bonilla $M .^{2}$
}

Con el propósito de evidenciar espacios de vecindad entre Søren Kierkegaard y Paul Tillich, pensadores nacidos en diversos siglos, y con el fin de poner en diálogo la filosofía y la teología, se expondrá, en primer lugar, cómo en el pensamiento existencial de Søren Kierkegaard el concepto de "interioridad" se constituye en un elemento fundamental de su obra, mientras el de "profundidad" es para Paul Tillich un componente capital en sus propuestas, para, seguidamente, dar cuenta de la posible influencia del primero sobre el segundo, a pesar de sus múltiples diferencias y contando también con ellas, y así explicitar algunos puntos de encuentro, al igual que algunas pistas de lectura que puedan dar lugar a afirmar la actualidad de varias de sus afirmaciones.

Palabras clave: interioridad, profundidad, Søren Kierkegaard, Paul Tillich, método de correlación.

\section{INTERIORITY AND DEPTH. RELATIONSHIP BETWEEN SØREN KIERKEGAARD AND PAUL TILLICH}

In order to demonstrate neighborhood spaces between Søren Kierkegaard and Paul Tillich, thinkers born in different centuries, and in order to put in dialogue philosophy and theology, be explained, first, how the thought of Søren Kierkegaard existential the concept of "interiority" constitutes a fundamental element of his work, while the "depth" is for Paul Tillich a critical component in their proposals and, then, to account for the possible influence of the former over the latter to despite their many differences and also having them, and so explain some points of contact and reading clues that may lead to the present state of several of his claims.

Keywords: Interiority, depth, Søren Kierkegaard, Paul Tillich, correlation method.

1 Este texto hace parte de los resultados de la investigación "Incidencia del pensamiento cristiano-existencial de Søren Kierkegaard en la propuesta de teología sistemática de Paul Tillich", adelantada por el autor en el grupo Kairos, perteneciente a la Universidad de San Buenaventura, sede Bogotá. Igualmente, quiere ser un temprano aporte en la celebración académica que se avecina en el marco del segundo centenario del nacimiento de Søren Kierkegaard (1813-2013).

2 Universidad de San Buenaventura, Bogotá, Colombia. Correo electrónico: jbonilla@usbbog.edu.co. 



\section{Desde la "interioridad" de Søren Kierkegaard}

El mundo categorial usado por Søren Kierkegaard es de amplio espectro. Su aporte, que apunta más a una filosofía de la existencia o a un pensamiento existencial que al existencialismo posterior, si aceptamos esta diferenciación, no se entiende fácilmente si se le encasilla o se le rotula sin recordar o reconocer la riqueza y la ambigüedad de su estilo, que complica la labor de quienes procuramos exponerlo ${ }^{3}$.

Para comprenderlo mejor es indispensable tener siempre presente su "punto de vista", a partir del cual declara que es un escritor religioso, que quiere llegar a ser cristiano y luchar contra la cristiandad 4 . Asimismo, denuncia a la sociedad de su tiempo porque "se ha olvidado totalmente lo que significa existir", al igual que ha dejado de comprender la verdad como subjetividad y como interioridad apasionada, por rendirse ante el facilismo de la objetivación, el esencialismo y la exterioridad del profesor de filosofía y el pastor, que tan solo buscan reconocimientos y gloria. Estas son las grandes preocupaciones de Kierkegaard, desde donde se pueden dilucidar las categorías que marcaron su derrotero. Nosotros queremos resaltar el concepto de "interioridad", ya que la denuncia de Kierkegaard sobre el olvido de lo que significa existir está ligada a la denuncia hacia las especulaciones de los sistemas, las construcciones objetivistas de la realidad y el pensamiento academicista de una filosofía que ha desestimado, en el olvido de la existencia, la pasión infinita de la interioridad.

Desde esta perspectiva, este filósofo danés considera que la verdad del cristianismo solo puede comunicarse de manera indirecta, con temor y temblor, no mediante la instrucción directa del profesor, pues de lo contrario el misterio se haría vulgar. Del mismo modo, pretende que todo discípulo, apartándose del maestro, sea para sí mismo su propia interioridad y no se limite a contemplar la de su maestro. Así, para todo ser humano, "la

3 Recordamos y asumimos la posición de José María Valverde, quien menciona los sarcasmos de Kierkegaard sobre quienes intentarán exponerlo, debido a una preocupación inicialmente estilística: "el temor a un malentendido como el que se produce cuando se expone en prosa lo dicho por un poeta en verso". VALVERDE, José María, "Kierkegaard: la dificultad del cristianismo", en FraiJó, Manuel (Ed.), Filosofía de la religión, Trotta, Madrid, 2005, p. 265.

4 Kierkegand, Søren, Mi punto de vista, Sarpe, Madrid, 1985, p. 30. Él diferencia radicalmente la cristiandad de lo que concibe como cristianismo. El primero haría referencia a la tergiversación o la mala comprensión del segundo, por lo que se configuraría en la expresión que denuncia como presente en su época.

5 Kierkegaard, Søren, Ejercitación del cristianismo, Trotta, Madrid, 2009, p. 144. 
interioridad de la verdad no es la afable interioridad de dos camaradas andando de la mano, sino que es la separación en virtud de la cual cada persona individualmente existe en aquello que es la verdad"'.

Tal vez por esa razón Rafael Larrañeta, uno de los estudiosos más reconocidos de la obra kierkegaardiana, opta por la verdad y el amor como elementos que articulan la forma como Kierkegaard hace su filosofía en cuanto interioridad apasionada. De este modo, poniendo el acento en la subjetividad de un existente, tiene lugar la interiorización. Pero, ¿qué es entonces la interioridad o en qué consiste la interiorización? "El núcleo de la reflexión subjetiva es la interiorización. Por ella puede llegar a ser la verdad. En esta vía nunca se olvida que el sujeto es existente y que existir es un devenir permanente"7. Así, la interiorización es el camino que reafirma la subjetividad y, por tanto, hace posible la verdad en cada existente.

De otra parte, el mismo Larrañeta, al retomar Las obras del amor de Kierkegaard, también hace énfasis en la interioridad como sustrato de esta forma de existir, pues el amor es el fundamento de la existencia. Y aunque el amor como interioridad no reniega inicialmente de su expresión común humana y, por tanto, su inflexión estética, para Kierkegaard el amor cristiano añade la decisión y la eternidad como elementos diferenciadores $^{8}$ y estos conducen hacia una mayor interioridad.

En este marco, la pregunta por la verdad va más allá de la adecuación del pensamiento con el ser o la adecuación del ser con el pensamiento, ya que lo realmente importante estaría determinado por aquello que se entienda como existencia, por el ser en su individualidad. Por ello afirma que la locura más peligrosa consiste en estar vaciado de interioridad, en ser un maniquí racional y especulativo. Este último sería el camino contrario al de la subjetividad y al de la conciencia de ser existente, el camino de la objetividad, es decir, de la no interioridad:

La reflexión subjetiva toma el camino interior hacia la subjetividad, y pretende ser en dicha interiorización la reflexión de la verdad, de suerte que, así como en el caso precedente se afirmaba la objetividad, y la subjetividad quedaba anulada, aqui la subjetividad se vuelve el factor decisivo y la objetividad desaparece. Y no olvidemos, ni aun por un solo instante, que el sujeto existe, y que existir es un devenir, y que la verdad concebida como la identidad entre pensamiento y ser no es, por tanto, sino una quimera de la abstracción y, a decir verdad, sólo un fruto del

6 Kierkegaard, Søren, Postcriptum no cientifico y definitivo a migajas filosóficas. Compilación mímico-patéticodialéctica, Universidad Iberoamericana, México, 2008, p. 251.

7 LARRAÑETA, Rafael, La interioridad apasionada. Verdady amor en Sören Kierkegaard, San Esteban, Salamanca, 1990, p. 251.

8 Cfr. Ibid., p. 203. 
ansia de la creación "no porque la verdad no sea una identidad", sino porque el cognoscente es un existente, $y$, por tal motivo, la verdad no puede ser para él una identidad en tanto sea existentes.

Por tanto, para Kierkegaard la verdad no se halla en el sujeto que tiene intereses objetivos y que se fija en la aproximación que le brinda la "idea" de Dios, sino que se encuentra en el existente que, apasionado, quiere saber si se relaciona con Dios y cómo se relaciona, pues "la pasión de lo infinito, no su contenido, es el factor decisivo, ya que su contenido es precisamente ella misma. De este modo, el 'cómo' subjetivo y la subjetividad son la verdad"10.

La dificultad estriba entonces en que el cristianismo, desde esta visión, se proclama como paradoja y como absurdo para el sujeto objetivo y para el pensamiento especulativo, pues se fundamenta en que la subjetividad da el acceso a la verdad, que la verdad es la pasión de la interioridad de la fe aferrada al absurdo, por lo que no le interesa ser comprendido. De tal manera que al cristianismo no le interesa la objetividad del pensamiento especulativo que se reduce a una aproximación, sino que reconoce que no hay verdad objetiva, ya que la verdad es sólo subjetiva, esto es, se da en la interioridad de la fe del creyente o en la pasión de la decisión individual. Por ello "saberse un credo de memoria es paganismo, porque el cristianismo es interioridad" rece de sentido que algún profesor se diga cristiano y pretenda superarlo por medio de sus explicaciones, pues piensa que el cristianismo sólo es verdad en cierto grado ${ }^{12}$. Este no es realmente el cristianismo, ya que el sujeto existente cristiano no debe dejarse seducir por la especulación, es decir, debe estar dispuesto a darlo todo, contando con lo improbable y la paradoja, incluso, inspirado en la pasión del infinito, reconoce el límite del entendimiento y cae en desesperación ${ }^{13}$, no para salir de ella y de manera inocente aferrarse a un nuevo conocimiento, sino para profundizar en su propia interioridad.

Entonces, "si la interioridad es la verdad, esta verdad es, objetivamente tomada, la paradoja. Que la verdad objetivamente sea paradoja, muestra que la subjetividad es la verdad, puesto que la repulsa de la objetividad da la medida de la tensión de la interioridad"14.

9 KierkegaArd, Søren, Postcriptum no cientifico y definitivo a migajas filosóficas. Compilación mímico-patéticodialéctica, op. cit.,pp. 198-199.

10 Ibid., p. 205.

11 Ibid., p. 226.

12 Esta afirmación la dirige Kierkegaard como parte de su constante crítica a Hegel.

13 La enfermedad mortal del espíritu es la desesperación y la desesperación es el pecado. Esta afirmación se desarrolla más ampliamente en dos libros: KierkegaArd, Søren, La enfermedad mortal, trad. de Demetrio Gutiérrez Rivero, Trotta, Madrid, 2008 y El concepto de la angustia, trad. de Demetrio Gutiérrez Rivero, Alianza, Madrid, 2007.

14 Kierkegaard, Søren, Postcriptum no cientifico y definitivo a migajas filosóficas. Compilación mímico-patéticodialéctica, op. cit., p. 75. 


\section{Desde la "profundidad" de Paul Tillich}

De otra parte, es posible considerar que la obra cumbre de Paul Tillich es su Teología sistemática, en donde manifiesta que "la teología oscila entre dos polos: la verdad eterna de su fundamento y la situación temporal en la que esa verdad eterna debe ser recibida"15. En esta distinción percibe el peligro de quienes solamente han optado por uno de los dos polos, hasta llegar al fundamentalismo o fanatismo. Por ello propone "buscar un método teológico en que el mensaje y la situación se relacionen de tal manera que no se eliminen entre s'́" 16 . En consecuencia surge su conocido método de correlación, que se da "entre las preguntas implícitas en la situación y las respuestas implícitas en el mensaje... entre preguntas y respuestas, situación y mensaje, existencia humana y autorrevelación divina"17. Y, en esta búsqueda, identificando el método como una aserción teológica, afirma que se configura de pasión y riesgo (elementos comunes a Kierkegaard). Éste sería el modo de ser y manifestarse del método propuesto, que daría cuenta de una preocupación mayor y que a su vez puede ser asumido como una postura, con la cual se comprenderán varios de sus argumentos:

El elemento decisivo en la actual situación del hombre occidental es la pérdida de la dimensión de profundidad. "Dimensión de profundidad" es una metáfora espacial: ¿qué significa cuando se la aplica a la vida espiritual del hombre, y se dice que es algo que éste ha perdido? Significa que el hombre ha perdido la respuesta a la pregunta por el sentido de su vida, la pregunta por el de dónde viene y a dónde va, la pregunta por lo que hace y debe hacer de sí en el breve lapso entre nacimiento y muerte ${ }^{18}$.

Tillich juzga el contexto sobre la base de la pérdida de la dimensión de profundidad e identifica este escenario con la pérdida del sentido de la vida, de lo que nos atañe incondicionalmente y la "dimensión religiosa". Por consiguiente, ser religioso sería lo mismo que retornar a la pregunta olvidada por el sentido de la vida, lo que atañe de manera incondicional y permanecer en la dimensión de profundidad. Desde esta perspectiva, se entiende que conciba la religión como "el ser mismo del hombre en cuanto se pone en juego el sentido de su vida y de la existencia en general"19.

15 Tillich, Paul, Teología Sistemática. Vol I. La razón y la revelación. El ser y Dios, Sígueme, Salamanca, 2009, p. 15.

16 Ibid., p. 21

17 Ídem.

18 Tillich,Paul, La dimensión perdida: indigencia y esperanza de nuestro tiempo, Desclée de Brouwer, Bilbao, 1970, p. 12.

19 Ibídem, p. 13. 
Ahora bien, en el plano de las religiones concretas, la pérdida de la profundidad es identificada por Tillich como la pérdida de significado de los símbolos específicos, aunque reconoce que la pregunta por el sentido de la vida permanece en las formas particulares que manifiestan la actitud religiosa del hombre contemporáneo y nos son propiamente religiones institucionales: "el arte moderno y la filosofía no son religiosos en el sentido estricto de la palabra; pero la pregunta religiosa se suscita en ellos con más urgencia y radicalidad que en la llamada literatura religiosa" ${ }^{20}$. Por esa razón resalta la dimensión de profundidad que puede darse en el novelista, el poeta, el dramaturgo, el pintor, el arquitecto, el filósofo analítico y existencial ${ }^{21}$, de tal manera que hay una "religiosidad perdida" y tal vez nunca reconocida, mucho más sincera y profunda que en muchos de quienes se dicen creyentes o religiosos.

El ejercicio de tomar conciencia de la pérdida de la dimensión de profundidad, podría ya ser parte de la respuesta a la pregunta religiosa, capaz de ir más allá de las ideologías seculares o creyentes ${ }^{22}$. Sólo a través de este camino la religión pude ir al encuentro de la dimensión perdida. Y así, en el reconocimiento de la profundidad a través de la religión, se podría vivificar la cultura. Por ello, "incluso olvidada, la fuerza de la profundidad sigue actuando; y más vigorosamente, allá donde su pérdida más profundamente se acusó” ${ }^{23}$.

Entonces, la religión de la que habla Tillich "no es ninguna función especial, es la dimensión de la profundidad en todas las funciones de la vida del espíritu humano"24. No puede confundirse o ser reducida a las funciones especiales como la ética, el conocimiento, la estética, el sentimiento, pues terminaría desvirtuada en su razón de ser, de ser aquello que nos atañe incondicionalmente y está presente en todas las anteriores. Pero, entonces:

\begin{abstract}
¿Qué significa esta metáfora de la profundidad? Significa que la dimensión religiosa apunta a aquel momento de la vida del espíritu humano que es último, infinito, incondicional. Religión, en el sentido más amplio y profundo de la palabra, es aquello que nos atañe incondicionalmente. $Y$ aquello que nos atañe incondicionalmente se manifiesta en todas las funciones creadoras del espíritu humano ${ }^{25}$.
\end{abstract}

De esta manera la religión sería "la substancia, el fundamento y la profundidad de la vida del espíritu humano" 26 . Y, por lo mismo, cuando no exista el abismo entre lo religioso (sagrado) y lo profano, "la religión volverá a ser lo que es en su esencia: el fundamento

20 Ídem.

21 Cfr. Ibídem, p. 19-21.

22 Ibídem, p. 23.

23 Ídem.

24 Ibidem, p. 28.

25 Ibidem, p. 31.

26 Ibidem, p. 32. 
omnicomplexivo y la substancia misma de la vida del espíritu humano"27. Para Tillich la indigencia de la religión radica, precisamente, en su separación de lo profano. Esta sería la situación trágica de la religión, el mundo real en el que se asume esta reflexión.

Desde esta perspectiva Tillich propone la esperanza como elemento unificador del horizonte vertical y horizontal de la religión, como catalizador del ámbito de la profundidad. Esta esperanza no es desencarnada, sino que por el contrario cuenta, ante todo, con lo que hay, con la imposición de la tragedia histórica y la respuesta que surge de la profundidad de la religión.

\section{Relación, influencia y actualidad}

No son pocos los filósofos que abierta o tácitamente han sido influenciados por Kierkegaard $^{28}$. Esta influencia también se da en el mundo de la teología, especialmente en la que se fundamenta en una filosofía de la existencia. Este es el caso de Paul Tillich.

De manera explícita Paul Tillich cita a Kierkegaard en diversas ocasiones. Una de ellas se da en su teología sistemática I, al exponer los dos criterios formales de toda teología, que consisten, en primer lugar, en la denominada "preocupación última", en contraposición a las preocupaciones preliminares, $y$, en segundo lugar, en la manera como toda teología debe remitir al ser o al no ser. En este marco afirma que la preocupación última exige la entrega de nuestra subjetividad, al igual que "suscita una pasión y un interés infinitos"29. Para hacer énfasis en la confluencia, recordemos que para Kierkegaard:

La pasión pertenece a la interioridad, está lejos de la vía objetiva. Los filósofos modernos han puesto especial énfasis en olvidarla, preocupándose poco o nada de ella. La pasión es capaz de transportar al sujeto existente a esa sintesis de infinito y finito que supera la existencia normal... la pasión correctamente entendida es el grado más alto de la existencia ${ }^{30}$.

Igualmente, en la Teología Sistemática II de Tillich, es citado Kierkegaard en repetidas ocasiones en la tercera parte, dedicada a La existencia y Cristo, para ubicar a Kierkegaard entre los existencialistas que atacan el esencialismo hegeliano ${ }^{31}$, para recordar que gracias

27 Ídem.

28 Entre estos se pueden contar a Heidegger, quien parece distanciarse y no reconocer ampliamente la influencia que pudo ejercer Kierkegaard sobre él, debido al talante religioso tan marcado y permanente, que lo alejaba de la filosofía que deseaba configurar. Cfr. LARRAÑETA, Rafael, op. cit., pp. 27-46. También se puede contar a Wittgenstein, que lo cita en diversas ocasiones y hasta lo llegó a considerar el filósofo más profundo del siglo XIX. Cfr. MartíneZ, Darío Ernesto, Wittgenstein y la religión, Tesis doctoral de la Pontificia Universidad Javeriana de Bogotá, 2010. Y en este elenco no puede faltar Unamuno, que resulta casi que amalgamado por el filósofo danés.

29 Tillich, Paul, Teología Sistemática. Vol I. La razón y la revelación. El ser y Dios, op. cit., p. 26.

30 LaRrañeta, Rafael, op. cit., pp. 68-69.

31 Cfr. Tillich, Paul, Teología Sistemática. Vol II. La existencia y Cristo, Sígueme, Salamanca, 1982, p. 42. 
a él el concepto de angustia-congoja es central en el existencialismo -en cuanto describe el paso del esencialismo al existencialismo y como característica de la libertad finita del ser humano- ${ }^{32}$ y para fundamentar el concepto de concupiscencia -que no significa el pecado generado por el ansia del placer sexual, sino el estado de alienación general- ${ }^{33}$.

Tillich también cita explícitamente a Kierkegaard en Se conmueven los cimientos de la tierra, obra en la que se publican varios de sus sermones con ese nuevo carácter "apologético", muy distinto al tradicional. Allí, en un sermón dedicado al "misterio del tiempo", retoma el concepto kierkegaardiano de la "Decisión", en el ahora que está cargado de experiencias religiosas ${ }^{34}$. En este estudio es posible ver similitudes que van más allá del escenario común de orden protestante-luterano y que trascienden la marca del siglo XIX que dejó Kierkegaard, así como la del siglo XX que dejó Tillich. La cercanía es evidente y los conceptos usados tan similares que vale la pena seguir desvelándolos, en concordancia con sus intereses filosóficos y teológicos, así como en la insistencia sobre la preponderancia que dan a la existencia humana y a la experiencia religiosa.

Ciertamente, somos conscientes de que este ejercicio interpretativo puede conducir a referenciar una similitud forzada entre el concepto de interioridad y profundad. Pero, consideramos que sí es posible inferir la influencia de Kierkegaard sobre Tillich en el marco de sus experiencias, pensamientos y escritos. Por tanto, no nos conformamos con afirmar que los dos conceptos expuestos superan el uso normal que se les ha dado en el lenguaje ordinario, ni que remiten a las fibras más entrelazadas de la existencia humana y a la vivencia comprometida y coherente con el cristianismo profesado por ambos. Según esto proponemos otras pistas de relación.

En primer lugar, una forma de afianzar la relación entre nuestros dos filósofos y teólogos, más allá de la exposición que aquí se ha hecho, tendría lugar desde la interpretación que José Luis Cañas ha realizado del pensamiento de Kierkegaard en su libro Entre la inmediatez y la relación. Precisamente allí se propone leer a Kierkegaard desde una nueva perspectiva, pues para él el "principal esquema intelectual inmediatez-relación sería el que mejor vertebra su creación y mejor moviliza las categorías filosóficas que maneja a lo largo de su vida y su obra" 35 . De esta manera los conocidos tres estadios de la vida son concebidos y reducidos realmente a dos maneras de ser humano, en donde Don Juan (el de Mozart y el del Diario de un seductor) representa la inmediatez, mientras que Abraham, como caballero de la fe (de Temor y Temblor), representa la relación. Esto es a lo que hace referencia Kierkegaard con su obra $O$ lo uno o lo otro, o inmediatez o relación, si bien es cierto que sería un error afirmar que esta diferenciación que parece tan radical implique la negación o anulación del estadio estético y todo lo que él conlleva.

32 Cfr. Ibidem, pp. 54-55.

33 Cfr. Ibidem, pp. 76-78.

34 Cfr. Tillich, Paul, Se conmueven los cimientos de la tierra, Ariel, Barcelona, 1968, p. 64.

35 CAÑas, José Luis, Søren Kierkegaard. Entre la inmediatez y la relación. Los dos estadios de la vida, Trotta, Madrid, 2003, p. 15. 
Estos estadios no pueden ser vistos como un camino unívoco que se sigue de manera procesual o acumulativa, sino que son formas de ser. Para ello Kierkegaard describió con detalle en qué consistía cada estadio, hasta el punto de dar a entender en muchas ocasiones que se trata de reinos totalmente distintos o separados por la "decisión". Sin embargo, él mismo es el ejemplo de la imposibilidad total de esta separación, en la medida en que la composición y aparición de sus obras no dan lugar a tres etapas sucedidas la una de la otra (estética, ética y religiosa), sino que son más que etapas, son estadios o esferas de la misma existencia ${ }^{36}$, en donde él quiere resaltar la esfera religiosa, pero no puede dejar a un lado las otras dos.

Una lectura de este tipo daría lugar a la posibilidad de dejar de lado algunos prejuicios que acompañan la interpretación común de la obra de Kierkegaard ${ }^{37}$, tal como que se trata de un simple pensador fideísta, angustiado y traumado por la maldición que profirió su padre y por su particular amor con Regina Olsen, en la opción que hizo por un amor más grande o transcendente; que estaría encerrado en una relación intimista con Dios y negaría las manifestaciones del mundo. Si bien el ideal de su vida era ser un verdadero cristiano, de manera radical, lo cierto es que en varias ocasiones reconoce que no lo es, que él no puede ser identificado con el caballero de la fe.

De este modo, la presente interpretación hace más expedito el propósito de identificar las similitudes entre el pensamiento de Kierkegaard con el método de correlación de Paul Tillich, habida cuenta de sus diferencias, al igual que una comprensión más amplia de la interioridad y la profundidad. Si bien es cierto que el primero rechaza en distintas ocasiones y con fuertes palabras la superficialidad y la falsedad del mundo, especialmente la del filosófico academicista y el pastor que busca ser maestro, no es menos cierto que Kierkegaard en la Ejercitación del cristianismo no condena el mundo y la historia. Lo que sí hace es dar a conocer la necesidad de subvertir el orden establecido (filosofía academicista y cristiandad), hasta el punto de luchar contra la intención de querer mundanizar incluso la relación con Dios en la interioridad: "El orden establecido quiere ser una totalidad, que no reconoce nada superior sobre sí, sino que tiene a cada individuo bajo su bota y juzga de cada individuo como subordinado a lo establecido"38. Así, presenta al mismo Cristo como modelo, ya que fue objeto de escándalo por no seguir lo establecido, por expresar la piedad

36 Ibidem, pp. 16-23.

37 Esto fue lo que se propuso Mariano Álvarez Gómez en el prólogo al libro La interioridad apasionada de Rafael Larrañeta. Planteó la posibilidad de identificar los prejuicios que se pueden superar: 1. Es un prejuicio pensar la angustia como actitud fundamental ligada inocentemente al pesimismo (De hecho, se entiende como la conciencia del ser finito). 2. Plantear la existencia con un significado radical, en donde es imposible una apertura a contenidos esenciales. 3. Creer que asumir la subjetividad como fundamento implica no obedecer o no aceptar normas objetivas. 4. Asumir la exaltación del individuo como rechazo a lo universal, en una suerte de decisionismo. 5. Considerar que al limitar radicalmente la razón se legitima el irracionalismo. 6. Entender el subjetivismo individualista como pasividad o rechazo de cualquier aporte en la transformación de la realidad. Cfr. Álvarez Gómez, Mariano, "Prólogo", en Larrañeta, Rafael, La interioridad apasionada. Verdad y amor en Søren Kierkegaard, op. cit., p. 11.

38 KierkegaArd, Søren, Ejercitación del cristianismo, op. cit., p. 107. 
desde la interioridad, no desde la exterioridad, ni desde prescripciones o tradiciones. No se trataría de una simple negación, sino de una transformación.

Es más, la vida entera del creyente debe ser considerada como una prueba o un examen para hacerse cristiano, pues Dios no aleja o suprime la realidad mundana y temporal. Esto nos muestra que es posible poner en correlación las preguntas del contexto y el mensaje de la revelación, la cultura y la religión, pero en la medida en que todo es guiado por la pasión de la interioridad. $\mathrm{O}$, desde la perspectiva de Tillich, desde la dimensión de profundidad, que de manera cercana a Kierkegaard, considera que lo profundo (la interioridad para Kierkegaard) está en relación directa con la verdad y el sufrimiento. Profundidad "significa o lo contrario de superficial o lo contrario de alto. La verdad no es superficial, es profunda. El sufrimiento es profundidad, no altura. La luz de la verdad y la oscuridad del sufrimiento son, las dos, profundas"39. Y, finalmente, la hace depender de Dios, pero no de manera impositiva ni radical (tal vez ya en disonancia con Kierkegaard, quien fue más radical):

El nombre de esta profundidad infinita y de este fundamento inexhausto de todo ser, es Dios. Esa profundidad es la que pensamos con la palabra Dios. Y si la palabra no posee para ustedes mucho significado, tradúzcanla entonces, y hablen de la profundidad en sus vidas, del origen de su ser, de aquello que les atañe incondicionalmente, de aquello que toman en serio sin reserva alguna. Cuando hagan esto, tendrán quizá que olvidar algunas de las cosas que aprendieron sobre Dios; quizá, incluso, la palabra misma. Porque, cuando hayan conocido que Dios significa profundidad, sabrán mucho de él ${ }^{40}$.

En segundo lugar, en concordancia con lo anterior, entre estas "coincidencias divergentes", si aceptamos con José Luis Cañas que "estadio para Kierkegaard significa un modo de concebir o realizar la propia existencia, una actitud existencial o nivel de realidad en el que plantea y orienta el hombre su existencia, y cada tipo de actitud ante la vida presenta una lógica peculiar, una articulación interna que engrana los diversos momentos de la actividad humana" ", entonces hallamos tanta similitud con la metáfora de "dimensión" que menciona Tillich, pues para él "las dimensiones tienen la particularidad de que se encuentran en un punto pero no intervienen las unas en las otras. No están yuxtapuestas ni superpuestas. Están entreveradas, y se unen en el punto en que se encuentran”42.

En tercer lugar, la respuesta a la pregunta por la verdad, latente en toda la obra de Kierkegaard, se ha dirigido sin más hacia la interioridad y la verdad subjetiva. No obstan-

39 Tillich, Paul, La dimensión perdida: indigencia y esperanza de nuestro tiempo, op. cit., p. 108.

40 Ibidem, p. 113.

41 Cañas, José Luis, op. cit., p. 25.

42 Tillich, Paul, La dimensión perdida: indigencia y esperanza de nuestro tiempo, op. cit., p. 85. 
te, consideramos que es posible contrastar dicho concepto de verdad o abrirlo a mayores posibilidades, ya que esta verdad (subjetividad) tendría un componente objetivo en doble dirección. Primero, en cuanto que a pesar de todo el rechazo a la especulación o a la academia, por parte del mismo Kierkegaard, su herencia se ha mantenido de una u otra forma gracias a ella. Y, segundo, en cuanto que hay algo ya establecido e inamovible como fuente, en la medida en que la verdad se identifica con Dios, un Otro distinto del sujeto humano y hacia éste se dirige toda la atención del creyente que quiere conocerlo y vivirlo.

Y, al mismo tiempo, esta verdad está fundada en el mundo subjetivo, en cuanto dicha fuente está caracterizada desde la revelación cristiana por la presencia de un sujeto divino, que incluso se hizo humano, al mismo tiempo que es comunicada o está disponible en la interioridad y profundidad de cada individuo.

En cuarto lugar, retomamos una consideración que se hecho sobre la persona y la obra de Kierkegaard, en cuanto él abría anunciado o previsto los problemas contemporáneos que se están presentando en relación con el mundo científico:

No es cierto que Kierkegaard fuera ciego para el ámbito de la verdad objetiva'. Cabe suponer lo contrario: a la vez que percibió que los conocimientos objetivos estaban garantizados en un progreso indefinido, se dio cuenta de que el individuo naufragaba entre tanto conocimiento. Al igual que otros muchos después de él, vio con una clarividencia radical que con el progreso de la ciencia peligraba el sentido de la vida. Y nadie que tenga sensibilidad para lo que hoy está ocurriendo podrá decir que no tenía razón. Él buscó la solución en una interioridad absoluta ${ }^{43}$.

En este mismo sentido, las razones de la pérdida de la dimensión de profundidad son propuestas claramente por Tillich: la ciencia, la técnica y la sociedad industrial que conducen a la supremacía de lo que él llama "dimensión horizontal”, caracterizada por la instrumentalización que el hombre hace del mundo, provisional y transitorio. Tillich afirma que la pérdida de la dimensión de profundidad está dada por el "fuerte interés por la investigación científica y la configuración técnica del mundo con la inclusión del influjo de ambas sobre el hombre mismo"44. Y el problema es que el ser humano resulta mimetizado en instrumento, un instrumento que no se sabe para qué sirve, carente de profundidad, pues no hace silencio ni reflexiona sobre el sentido de su vida, sino que prefiere distraerse a la pregunta.

En quinto y último lugar, consideramos que el método de correlación sería, de manera efectiva, la forma como Tillich pretende tender o evidenciar los puentes de relación

43 Álvarez Gómez, Mariano, op. cit., p. 13.

44 Tillich, Paul, La dimensión perdida: indigencia y esperanza de nuestro tiempo, op. cit., p. 67. 
entre lo humano y lo divino, el mensaje y el contexto, la objetividad y la subjetividad. No podemos afirmar de manera inocente que sigue al pie de la legra a Kierkegaard o que su influencia es absoluta, pero sí podemos determinar su cercanía en la insistencia que hace Tillich sobre la existencia subjetiva, que deriva de manera propia en el compromiso humano de aceptación y valoración de las culturas y, especialmente, en la esperanza o lo que implica esperar:

Nuestro tiempo es un tiempo de espera; esperar es su especial destino. $Y$ todos los tiempos son tiempos de espera, la espera de la irrupción de la eternidad. Todos los tiempos se apresuran. Todos los tiempos, tanto en la historia como en la vida personal, son expectación. El tiempo mismo es una espera, no de otro tiempo, sino de lo que es eterno ${ }^{45}$.

Aquí asumimos que la forma efectiva de esperar es a partir del marco de lo que se concibe como la "decisión kierkegaardiana" que compromete la totalidad de la existencia, en el instante de la decisión en que cada ser humano, más allá de la institución, la historia, la tradición y el contexto, sin necesidad de negarlos, acoge o rechaza la profunda tensión de la espera, en la interioridad de lo que se vive, se piensa o se anhela. Y así, consideramos que el método de correlación, releído desde esta intencionalidad argumentativa, tiene la posibilidad de desplegar horizontes de aplicación aún inexplorados.*

\section{Bibliografía}

Álvarez Gómez, Mariano, "Prólogo", en Larrañeta, Rafael, Interioridad apasionada. Verdad y amor en Søren Kierkegaard, San Esteban-Universidad Pontificia, Salamanca, 1990.

Cañas Fernández, José Luis, Søren Kierkegaard. Entre la inmediatez y la relación. Los dos estadios de la vida, Trotta, Madrid, 2003.

Kierkegaard, Søren, Ejercitación del cristianismo, Trotta, Madrid, 2009.

Postcriptum no científico y definitivo a migajas filosóficas. Compilación mímico-patético-dialéctica, Universidad Iberoamericana, México, 2008.

, La enfermedad mortal, trad. de Demetrio Gutiérrez Rivero, Trotta, Madrid, 2008.

45 Tillich, Paul, Se conmueven los cimientos de la tierra, op. cit., p. 24.

*Artículo recibido: 28 de junio de 2012. Aceptado: 3 de septiembre de 2012. 
----------------, El concepto de la angustia, trad. de Demetrio Gutiérrez Rivero, Alianza, Madrid, 2007.

Las obras del amor: meditaciones cristianas en formas de discursos, Sígueme, Salamanca, 2006.

, O lo uno o lo otro. Un fragmento de vida I, Trotta, Madrid, 2006.

---------------, Mi punto de vista, trad. de José Miguel Velloso, Sarpe, Madrid, 1985.

LARrañeta, RAfael, La interioridad apasionada. Verdad y amor en Søren Kierkegaard, San Esteban-Universidad Pontificia, Salamanca, 1990.

Martínez, Darío Ernesto, Wittgenstein y la religión, Tesis doctoral de la Pontificia Universidad Javeriana de Bogotá, Bogotá, 2010.

Tillich, Paul, Teología Sistemática. Vol I. La razón y la revelación. El ser y Dios, Sígueme, Salamanca, 2009.

---------, Teología Sistemática. Vol II. La existencia y Cristo, Sígueme, Salamanca, 1982.

La dimensión perdida: indigencia y esperanza de nuestro tiempo, Desclée de Brouwer, Bilbao, 1970.

---------, Se conmueven los cimientos de la tierra, Ariel, Barcelona, 1968.

VAlverde, José María, “Kierkegaard: la dificultad del cristianismo”, en Fraijó, Manuel (Ed.), Filosofía de la religión, Trotta, Madrid, 2005. 